\title{
ALGUNAS ESPECIES DE HYPOXYLON (PYRENOMYCETES, XYLARIACEAE) DE MEXICO
}

\author{
Felipe Eduardo San Martin \\ Instituto Tecnológico de Cd. Victoria \\ Apartado postal 175 \\ 87010 Cd. Victoria, Tamaulipas \\ E-mail: biota@correo.tamnet.com.mx \\ Yu-Ming Ju y Jack D. ROgers \\ Department of Plant Pathology \\ Washington State University \\ 99164 Pullman, Washington \\ USA \\ E-mail: rogers@wsu.edu
}

\section{RESUMEN}

Se presenta una clave artificial para 41 especies y tres variedades del género Hypoxylon sensu stricto, recolectadas en México al presente; 31 especies y una variedad pertenecen a la sección Hypoxylon, mientras que 10 especies y dos variedades corresponden a la sección Annulata. Dos taxa permanecen sin epíteto específico debido a la escasez del material o a la carencia de datos sobre sus anamorfos. Se propone como nueva a Hypoxylon shearii var. minor. Para cada taxon se proporcionan datos sobre distribución, substratos, fechas de recolecta y, en algunas, notas sobre afinidades con otras especies del género.

\section{ABSTRACT}

An artificial key to 41 species and 3 varieties of the genus Hypoxylon sensu stricto collected in Mexico so far, is presented; 31 species and one variety belong to section Hypoxylon whereas 10 species and 2 varieties correspond to section Annulata. Two taxa remain without specific epithet due the scarcity of the material or the lack of anamorphic data. The new variety Hypoxylon shearii var. minor is proposed. Data on distribution, substrates, collecting dates, and affinities with other species of the genus, are provided for most taxa.

\section{INTRODUCCION}

De los hongos Ascomycetes de la familia Xylariaceae, Hypoxylon, después de Xylaria, es el género con mayor número de especies en el territorio mexicano (San Martín, 1992). La revisión mundial del género por Ju y Rogers (1996) y el trabajo de Van der Gucht 
et al. (1997) hecho en Papua, Nueva Guinea, arrojan un total de 121 especies, de tal manera que México con 41, cuenta con $34 \%$ de esa cantidad global. El número de componentes de Hypoxylon presentes en el país debe ser mayor si se considera que no se ha explorado micológicamente, de una manera minuciosa, ni la mitad del territorio de la República. Por lo anterior es de esperarse la existencia en México de especies ya citadas de otras latitudes y por supuesto también de otras nuevas para la ciencia.

Los miembros del género viven como saprótrofos o patógenos débiles en madera de árboles de clima templado o (principalmente) tropical (Miller, 1961), o como endófitos (quizás en simbiosis mutualista) en los tejidos internos de plantas leñosas o herbáceas (Petrini y Petrini, 1985).

Hypoxylon tiene estrecha afinidad con Entonaema y Daldinia debido a que comparte con ellos la conexión anamórfica del tipo Nodulisporium y caracteres teleomórficos como la presencia de pigmentos estromáticos, la morfología del anillo apical de los ascos (más ancho que alto), el episporio conspicuo y generalmente dehiscente en $\mathrm{KOH}$ a 10\%, así como la localizacíón de la línea germinal por lo regular dorsal y recta, raramente sigmoide o espiral, en las ascosporas (Ju et al., 1997; San Martín y Lavín, 1997).

Esta contribución es el resultado de 12 años de trabajo de campo y laboratorio, en ella se provee una clave artifical para 41 especies y tres variedades del género; asimismo, se comunican datos sobre su distribución, substratos, fechas de recolecta y afinidades con otros componentes del grupo.

Los caracteres usados para la determinación taxonómica de las especies son los que toman en cuenta Ju y Rogers (1996) y Van der Gucht et al. (1997), y las identificaciones que haga el usuario de la clave deberán ser comparadas con las descripciones plasmadas en dichas referencias, a reserva de que se indique lo contrario más adelante en el texto de este trabajo.

Los colores, tanto de estromas como de pigmentos, se dan de acuerdo con Reyner

Para los acrónimos de herbarios se sigue a Holmgren et al. (1990). Los ejemplares se encuentran depositados en ITCV, WSP y en los herbarios personales de Ascomycetes de Felipe San Martín (FSM con registro en trámite) y Jack D. Rogers (JDR).

\section{CLAVE ARTIFICIAL PARA LAS ESPECIES MEXICANAS DE HYPOXYLON}

1 Estromas maduros con la superficie coloreada, raramente negruzca; tejido estromático que circunda a cada peritecio no carbonizado; ostiolos por lo regular abajo de la superficie estromática (umbilicados), infrecuentemente al mismo nivel o algo más arriba de la superficie estromática (papilados), usualmente no rodeados por un disco anillado; perisporio, de ser dehiscente, con una ornamentación helicoidal visible conspicua o inconspicua (Sección Hypoxylon)

\section{2}

1 Estromas maduros con la superficie negruzca, raramente coloreada; tejido estromático que circunda a cada peritecio, carbonizado; ostiolos por lo regular al mismo nivel o arriba de la superficie estromática (papilados), rodeados o no por un disco anillado; perisporio, de ser dehiscente, con un área engrosada visible de ca. 1/3 de la longitud de la ascospora a partir de un extremo, en el mismo lado en que se presenta la línea germinal (Sección Annulata) 37 
2 Estromas con la superficie de color azul ciano (27) u oliváceo (48) .......................... 3

2 Estromas con la superficie de otros colores .............................................................. 4

3 Estromas con la superficie de color azul ciano (27) con gránulos negruzcos que contienen pigmentos extraíbles con $\mathrm{KOH}$ de color ámbar (9) o rojo vino (85); ascosporas de color café claro a café, elipsoides casi equilaterales, con extremos redondeados o con menos frecuencia estrechamente redondeados, de 7-11.5 x 4-5 $\mu \mathrm{m}$, con línea germinal inconspicua, algo menor que la longitud total de la ascospora; perisporio indehiscente en $\mathrm{KOH}$ a $10 \%$.... H. aeruginosum

3 Estromas con la superficie de color oliváceo (48), con gránulos de color rojo anaranjado que contienen pigmentos extraíbles con $\mathrm{KOH}$ de color anaranjado (7); ascosporas de color café a café obscuro, elipsoides inequilaterales, con extremos estrechamente redondeados, de 9.5-11 x 4-5 $\mu \mathrm{m}$, con línea germinal conspicua, recta a ligeramente sigmoide, a todo lo largo del propágulo; perisporio dehiscente en $\mathrm{KOH}$ a $10 \%$

H. olivicolor

4 Estromas hemisféricos a esféricos, usualmente de más de $1.5 \mathrm{~mm}$ de grueso; con gránulos de color rojo anaranjado inmediatamente abajo de la superficie que contienen pigmentos extraíbles con $\mathrm{KOH}$ de color anaranjado (7), con gránulos de color blanco entre los peritecios; ascosporas de color café obscuro, elipsoides inequilaterales, con extremos estrechamente redondeados, de 7-9.5(-10) x 3-4.5 $\mu \mathrm{m}$, con línea germinal recta a todo lo largo del propágulo; perisporio dehiscente en $\mathrm{KOH}$ a $10 \%$

H. howeianum

4 Combinación de caracteres diferente a la de arriba. Sin gránulos de color blanco entre los peritecios

5 Estromas peltados, placentiformes, hemisféricos o esféricos, con endostroma masivo, usualmente con más de $2.5 \mathrm{~mm}$ de grueso; con gránulos de colores pálidos inmediatamente bajo la superficie que contienen pigmentos extraíbles con $\mathrm{KOH}$ de colores diferentes a la serie de los anaranjados; tejido homogéneo entre los peritecios y bajo la capa peritecial; peritecios usualmente tubulares

5 Estromas de formas diferentes a las de arriba, con endostroma delgado, usualmente de menos de $2.5 \mathrm{~mm}$ de grueso; gránulos de varios colores inmediatamente abajo de la superficie y entre los peritecios, con pigmentos extraíbles con $\mathrm{KOH}$ de varios colores o ausentes en estado maduro; peritecios raramente tubulares

6 Estromas con pigmentos extraíbles con $\mathrm{KOH}$ de color oliváceo (48), verdoso (90), isabelino (65), verde pálido (70) o infrecuentemente sin pigmentos aparentes; ascosporas de color café a café obscuro, elipsoides inequilaterales, con extremos estrechamente redondeados, de 8.5-18.5 x 4.5-8(-8.5) $\mu \mathrm{m}$, con línea germinal recta a todo lo largo del propágulo; perisporio dehiscente en $\mathrm{KOH}$ a $10 \%$

H. placentiforme

6 Estromas con pigmentos extraíbles con $\mathrm{KOH}$ de color púrpura o sin pigmentos; ascosporas con la línea germinal corta; perisporio no dehiscente en $\mathrm{KOH}$ a $10 \%$

7 Estromas con la superficie de color café claro (87), ladrillo obscuro (60) o sepia (63); ascosporas de color café a café obscuro, elipsoides, de forma muy variable, algo inequilaterales, con extremos estrechamente redondeados, de 9.5-12(-13) x 4-5 $\mu \mathrm{m}$, con línea germinal recta, frecuentemente en el lado cóncavo H. symphyon 
7 Estromas con la superficie de color café rojo vino (84) o sepia (63); ascosporas de color café claro a café, de forma menos variable, de 11.5-14 x 5-5.5 $\mu \mathrm{m}$, con línea germinal recta, en el lado convexo H. polyporum

8 Ostiolos papilados; superficie estromática de color negruzco en la madurez ................ 9

8 Ostiolos umbilicados 0 , con menos frecuencia, al mismo nivel de la superficie estromática, de ser papilados, la superficie estromática coloreada en la madurez 11

9 Ascosporas de color café claro a café, elipsoides, casi equilaterales, con extremos redondeados a estrechamente redondeados, de 12.5-14.5 x 6.5-7.5 $\mu \mathrm{m}$, con línea germinal recta a algo sigmoide a todo lo largo del propágulo; perisporio no dehiscente en $\mathrm{KOH}$ a $10 \%$ H. sp. San Martín 227

9 Ascosporas de color café a café obscuro, elipsoides inequilaterales, con extremos estrechamente redondeados o algo aguzados; perisporio dehiscente en $\mathrm{KOH}$ a $10 \%$; estromas jóvenes con la superficie de color rojo ladrillo (39) a sepia (63), con pigmento extraíble en $\mathrm{KOH}$ a $10 \%$ de color sepia (63); estromas maduros sin pigmentos ...... 10

10 Ascosporas de $7-11 \times 3.5-4.5(-5) \mu \mathrm{m}$, con línea germinal sigmoide a todo lo largo del propágulo

H. monticulosum

10 Ascosporas de 11-16 x 5-5.5 $\mu \mathrm{m}$, con línea germinal recta a todo lo largo del propágulo H. rubigineoareolatum

11 Ascosporas equilaterales, con menos frecuencia ligeramente inequilaterales, con perisporio dehiscente o indehiscente en $\mathrm{KOH}$ a $10 \%$.

11 Ascosporas conspicuamente inequilaterales, con perisporio dehiscente en $\mathrm{KOH}$ a $10 \%$

Ascosporas con perisporio no dehiscente en $\mathrm{KOH}$ a $10 \%$

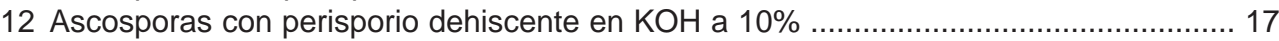

13 Superficie estromática carente de tonos de color rojo vino ........................................ 14

13 Superficie estromática con tonos de color rojo vino ........................................................15

14 Estromas con gránulos de color rojo anaranjado brillante; ascosporas de color café a café obscuro, con extremos redondeados a estrechamente redondeados, de 9.5-14 x 5-7.5 $\mu \mathrm{m}$, con línea germinal recta, algo menor o a lo largo del propágulo

H. cinnabarinum

14 Estromas con gránulos de color rojo ladrillo a café anaranjado pálido; ascosporas de color café obscuro, con extremos redondeados, de 7.5-10 x 4.5-6 $\mu \mathrm{m}$, con línea germinal recta a todo lo largo del propágulo ............................ H. sp. San Martín 23

15 Estromas con pigmentos extraíbles con $\mathrm{KOH}$ de color miel (65), ámbar (47), isabelino (65), amarillo verdoso (16), verde pálido (70) o verde obscuro (21); peritecios de forma oblonga a tubular, de 0.3-0.4 mm de diámetro x 0.5-1 mm de alto; ascosporas de color café claro a café, de (6-)6.5-9.5(-10) x 3-4.5 $\mu \mathrm{m}$, con línea germinal inconspicua, menor a algo menor que la longitud total del propágulo H. investiens

15 Combinación de caracteres diferente a la de arriba 16

16 Estromas con gránulos de color anaranjado pálido a café-amarillento o con pigmentos extraíbles con $\mathrm{KOH}$ de color lúteo (12), anaranjado (7) o escarlata (5). Peritecios obovoides, de 0.2-0.3 mm de diámetro x 0.45-0.8 $\mathrm{mm}$ de alto; ascosporas de color café obscuro, elipsoidales, casi equilaterales, con extremos redondeados, de (6.5-)7-9(-10.5) x 5-5.5(-6.5) $\mu \mathrm{m}$, con línea germinal recta, muy corta H. cf. samuelsii 
16 Estromas con gránulos de color café obscuro a negro, sin pigmentos extraíbles con $\mathrm{KOH}$ o de estar presentes, de color gris sepia diluido (106). Peritecios de forma oval, de 0.1-0.3 mm de diámetro x 0.2-0.4 mm de alto; ascosporas de color café claro a café, elipsoides, casi equilaterales con extremos redondeados, de 6.5-10(-11) x (3-)3.5-4 $\mu \mathrm{m}$, con línea germinal inconspicua por lo regular a todo lo largo de la ascospora

H. dieckmannii

17 Superficie estromática con tonos de color rojo vino; ascosporas fusoides, cortas, casi equilaterales, de (6.5-)7-9 × 3-4 $\mu \mathrm{m}$, con línea germinal algo oblicua a sigmoide, corta, o menos frecuentemente extendida a lo largo del propágulo H. hypomiltum

17 Superficie estromática sin tonos de color rojo vino; ascosporas fusoides a elipsoides, casi inequilaterales a inequilaterales, de (7-)7.5-9.5 x 3-4.5 $\mu \mathrm{m}$, con línea germinal extendida casi o a todo lo largo del propágulo H. erythrostroma

18 Estromas glomerulados, por lo regular con protrusiones periteciales muy conspicuas, usualmente con la mitad o la totalidad de la protrusión expuesta; con gránulos estromáticos de color café anaranjado a café obscuro, con pigmentos extraíbles con $\mathrm{KOH}$ de color castaño (88), grisáceo (8), canela (62), café-amarillento (43), ámbar (9) u ocre (44); ascosporas de color café a café obscuro, de 9.5-15(-16) x 4-6.5(-7) $\mu \mathrm{m}$ H. lenormandii

18 Estromas planos o con protrusiones periteciales inconspicuas o conspicuas 19

19 Estromas con gránulos de color café pálido, café rojizo o negros, con pigmentos extraíbles con $\mathrm{KOH}$ de color púrpura claro [lívido obscuro (80), violeta obscuro (33), púrpura diluido (81) o violeta diluido (79)]; ascosporas de 10-13.5(-15) x 4.5-6 $\mu \mathrm{m}$

H. lividipigmentum

19 Combinación de caracteres diferente a la de arriba 20

20 Estromas con gránulos de color rojo anaranjado, anaranjado, anaranjado pálido, café anaranjado, café amarillento, rojizo, o menos frecuentemente café pálido, con pigmentos extraíbles con $\mathrm{KOH}$ de color anaranjado, rojizo o rojo ladrillo [anaranjado (7), lúteo (12), ocre (44), grisáceo (8), escarlata (5), café-amarillento (43) o rojo ladrillo (39)]

20 Estromas con gránulos de color café claro, café pálido, café rojizo o negro, con pigmentos extraíbles con $\mathrm{KOH}$ de color amarillo, amarillo verdoso, verde pálido $\mathrm{u}$ oliváceo [amarillo (14), ámbar (47), amarillo con tonos amarillo verdoso (14), isabelino (65), miel (64), castaño (88), oliváceo (48), oliváceo verdoso (90), verde pálido (70), oliváceo gris (107) o gris oliváceo (121)]; si el estroma contiene gránulos de color anaranjado pálido o café anaranjado, entonces con pigmentos extraíbles con $\mathrm{KOH}$ de color diferente a los mencionados en la opción de arriba 31

21 Ascosporas mayores de $14 \mu \mathrm{m}$ de largo y de más de $6.5 \mu \mathrm{m}$ de ancho .................. 22

21 Ascosporas menores de $14 \mu \mathrm{m}$ de largo y de menos de $6.5 \mu \mathrm{m}$ de ancho ............. 23

22 Superficie estromática de color sepia (60); peritecios de forma esférica, de 0.3-0.4 mm de diámetro; estípites ascales de menos de $150 \mu \mathrm{m}$ de largo; ascosporas de 15-18 x 6.5-7.5 $\mu \mathrm{m}$

H. sp. aff. ferrugineum

22 Superficie estromática de color café-amarillento (43), grisáceo (8) o rojo ladrillo (39); peritecios tubulares, de 0.3-0.6 mm de diámetro $\times 0.8-2.5(-3) \mathrm{mm}$ de alto; estípites ascales mayores de $150 \mu \mathrm{m}$ de largo; ascosporas de 13.5-18(-19) x 7-8(-8.5) $\mu \mathrm{m}$ 
23 Estromas con gránulos de color café amarillento o café; ascosporas de (8-)9-12 x 4-5.5 $\mu \mathrm{m}$ H. cf. rubiginosum

23 Estromas con gránulos de colores brillantes i.e., anaranjado amarillento, anaranjado o rojo anaranjado 24

24 Superficie estromática con tonos de color rojo vino; ascosporas de (8-)9-12 x 4-5.5 $\mu \mathrm{m}$

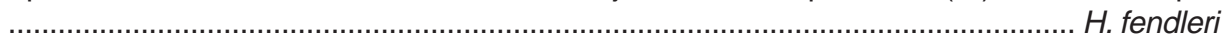

24 Superficie estromática sin tonos de color rojo vino .................................................. 25

25 Ascosporas mayores de $9.5 \mu \mathrm{m}$ de largo y de más de $4.5 \mu \mathrm{m}$ de ancho ................. 26

25 Ascosporas menores de $9.5 \mu \mathrm{m}$ de largo y de menos de $4.5 \mu \mathrm{m}$ de ancho ............ 27

26 Ascosporas de (9-)9.5-15(-17.5) x 4-7(-7.5) $\mu \mathrm{m}$; conidios de 5-7.5 x 3-4 $\mu \mathrm{m}$

H. crocopeplum

26 Ascosporas de 7-11 x 3.5-5 $\mu$; conidios de 3-4.5 x 1.5-2 $\mu \mathrm{m}$...................... H. subgilvum

27 Peritecios de 0.3-0.5 mm de diámetro x 0.5-0.8 mm de alto; superficie estromática de color rojo ladrillo (39) o grisáceo (8); ascosporas de 6.5-8 x 3-4 $\mu \mathrm{m}$.................. H. rickii

27 Peritecios menores de $0.3 \mathrm{~mm}$ de diámetro ...................................................... 28

28 Superficie estromática de color rojo ladrillo (39), sepia (63), bayo (6) o rojo ladrillo obscuro (60), con gránulos de color rojo anaranjado bajo la superficie y entre los peritecios; con pigmentos extraíbles con $\mathrm{KOH}$ de color anaranjado (7); ascosporas de 5-5.5 x $2.5 \mu \mathrm{m}$, con línea germinal recta a algo sigmoide, ubicada a todo lo largo del propágulo H. sp. aff. ticinense

28 Combinación de caracteres diferente a la de arriba; ascosporas mayores ................ 29

29 Superficie estromática usualmente de colores obscuros i.e., café obscuro a negruzco; peritecios de forma esférica a obovada; ascosporas de color café claro a café, fusoides a elipsoides, moderadamente inequilaterales a inequilaterales, con extremos casi agudos, de (7-) 7.5-9.5 × 3-4.5 $\mu \mathrm{m}$

H. erythrostroma

29 Superficie estromática de colores más claros i.e., ocráceo, café anaranjado claro o rojo ladrillo; peritecios de forma obovada, oblonga o tubular 30

30 Estromas con la superficie de colores predominantemente ocráceos [café-amarillento (43), ocre (44) o durazno (42)]; ascosporas de 8-9.5(-11) x 4-5 $\mu \mathrm{m}$ H. jecorinum

30 Estromas con la superficie de colores predominantemente rojizos [ámbar (9), sepia (63), rojo ladrillo (39), grisáceo (8), ladrillo obscuro (60) o bayo (6)]; ascosporas de 7-11

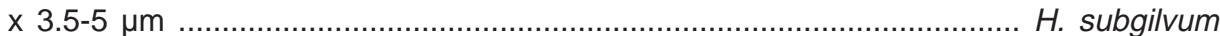

31 Estromas glomerulados conteniendo varios peritecios ........................................... 32

31 Estromas usualmente pulvinados a efuso-pulvinados conteniendo muchos peritecios 33

32 Superficie estromática cuando joven de color café claro (45), café (87) o rojo vino (86), cuando madura con gránulos de color amarillo a anaranjado amarillento inmediatamente bajo la superficie y entre los peritecios, con pigmentos extraíbles con $\mathrm{KOH}$ de color lúteo (12); ascosporas de color café obscuro, de 10.5-15 x 5.5-7 $\mu \mathrm{m}$

H. sheariivar. shearii

32 Superficie estromática y pigmentos como arriba; ascosporas de color café, de (6.5-)7-8 $\mathrm{x}(3-) 3.5-4 \mu \mathrm{m}$ H. shearii var. minorvar. nov.

33 Perisporio con ornamentación helicoidal muy conspicua ............................................ 34

33 Perisporio liso o con ornamentación helicoidal inconspicua .................................... 35 
34 Ascosporas de color café obscuro, de 13-23(-24) x (6-)6.5-10(-10.5) $\mu \mathrm{m}$

34 Ascosporas de color café a café obscuro, de 9.5-13(-14.5) x 4.5-6.5 $\mu \mathrm{m}$ H. duranii

35 Superficie estromática de color rojo vino (84), café (87) o ladrillo obscuro (60), con pigmentos extraíbles con $\mathrm{KOH}$ de color isabelino (65), ámbar (9) o gris sepia (106); peritecios de forma obovada a oblonga, de 0.3-0.6 mm de diámetro $\times$ 0.6-0.9 mm de alto; ascosporas de 9-12.5(-13) x 4-5.5 $\mu \mathrm{m}$ H. cf. macrocarpum

35 Peritecios usualmente de menos de $0.3 \mathrm{~mm}$ de diámetro; combinación de caracteres diferente 36

36 Estromas con pigmentos extraíbles con $\mathrm{KOH}$ de color ámbar (47) con tonos amarilloverdosos (16), o amarillo verdoso (16) con tonos citrinos (13); ostiolos por lo regular cubiertos por una substancia blanca llamativa; ascosporas de (8-)9-12(-13) x 4-6 $\mu \mathrm{m}$

H. perforatum

36 Estromas con pigmentos extraíbles con $\mathrm{KOH}$ de color isabelino (65), oliváceo (48), oliváceo gris (107), oliváceo verdoso (90) o ámbar (47); ostiolos no cubiertos por una substancia blanca llamativa; ascosporas de 8.5-13.5 x 4-6 $\mu \mathrm{m}$

H. anthochroum

37 Estromas de forma constantemente hemisférica a esférica; con gránulos de color negruzco inmediatamente abajo de la superficie; con pigmentos extraíbles con $\mathrm{KOH}$ de color verde pálido (70); ascosporas de color café claro a café, elipsoides inequilaterales, comúnmente colapsadas, con perisporio no dehiscente, casi siempre con arrugas longitudinales; especie invariablemente asociada a Quercus spp.

37 Estromas de formas y colores varios; ascosporas con perisporio dehiscente, más o menos liso; especies asociadas a Quercus y otras dicotiledóneas 39

38 Ascosporas de 14-24 x 4.5-5 $\mu \mathrm{m}$ H. thouarsianum var. thouarsianum

38 Ascosporas de 24-27(-30) x 6-7 $\mu \mathrm{m}$ H. thouarsianum var. macrosporum

39 Estromas con ostiolos no rodeados por un disco; ascosporas con línea germinal menor que la longitud total del propágulo

39 Estromas con ostiolos rodeados por un disco; ascosporas con línea germinal menor o igual a la longitud total del propágulo

40 Estromas por lo regular de forma hemisférica, obcónica o escutelada, con la base conspicuamente constreñida, usualmente con un grosor mayor de $2.5 \mathrm{~mm}$, con pigmentos extraíbles con $\mathrm{KOH}$ de color rojo diluido (56), rojo vino (57), ladrillo (59) o bayo (6); superficie negruzca cuando madura; tejido basal conspicuo; ascosporas de 6.5-7.5(-8) x 3-4 $\mu \mathrm{m}$

H. cohaerens var. microsporum

40 Estromas escutelados con la superficie convexa y la base constreñida, usualmente con más de $2.5 \mathrm{~mm}$ de grueso, con pigmentos extraíbles con $\mathrm{KOH}$ de color oliváceo (48) a oliváceo verdoso (90); superficie negra cuando madura; tejido basal conspicuo; ascosporas de 8.5-12 x 3.5-5 $\mu \mathrm{m}$

H. multiforme

41 Estromas discoides a escutelados, unidos al substrato por una conexión estrecha; ascosporas de color café claro, con extremos redondeados, de 7.5-10 x 3-4 $\mu \mathrm{m}$, con línea germinal inconspicua, recta, corta H. pseudostipitatum

41 Estromas efuso pulvinados, glomerulados o hemisféricos, unidos al substrato por toda la base; ascosporas con línea germinal conspicua 42 
42 Ascosporas de 5-7 x 2-3 $\mu$ m, con la línea germinal ubicada en el lado cóncavo; peritecios de forma obovada a oblonga, de 0.2-0.3 mm de diámetro x 0.4-0.6 mm de alto; disco ostiolar de 0.1-0.2 mm de diámetro H. stygium

42 Ascosporas con la línea germinal ubicada en el lado convexo ............................... 43

43 Estromas maduros de color negro brillante; ascosporas de 6.5-10 x 3-4.5 $\mu \mathrm{m} \ldots \ldots \ldots . . .44$

43 Estromas maduros de color café pálido, negruzco o con tonos oliváceos

44 Estromas con pigmentos extraíbles con $\mathrm{KOH}$ de color verdoso (90) 45

44 Estromas con pigmentos extraíbles con $\mathrm{KOH}$ de color rojo vino (101) o gris-violeta (116) H. purpureonitens

45 Estromas glomerulados, pulvinados, hemisféricos o efuso pulvinados, con protrusiones periteciales conspicuas o inconspicuas; de color negruzco con tonos oliváceos; ascosporas de 6-9 x 2.5-4 $\mu \mathrm{m}$; hospedantes diferentes a Quercus spp. ..... H. moriforme

45 Estromas de colores y formas varios; hospedantes del género Quercus 46

46 Estromas hemisféricos, por lo regular sin protrusiones periteciales conspicuas, de color café negruzco con tonos oliváceos; ascosporas de color café a café obscuro, de 7.5$10.5(-11) \times 3.5-5(-6) \mu \mathrm{m}$ H. annulatum

46 Estromas glomerulados a efuso pulvinados, por lo regular con protrusiones periteciales conspicuas, de color café obscuro con tonos rojizos; ascosporas de color café a café obscuro; de 8-10.5 x 4-5 $\mu$ m; comúnmente asociado con $H$. annulatum, más no muy frecuentemente recolectado..... H. truncatum

\section{SECCIÓN HYPOXYLON}

Hypoxylon aeruginosum J. H. Miller, Mycologia 25: 321.1933.

Espécimen examinado: Quintana Roo, municipio de Othón P. Blanco, San Felipe Bacalar, 7.XII.1986, San Martín 32, sobre madera en un acahual (ITCV; JDR).

Espécimen adicional examinado: Guyana, Pt. Voyhed, 2.II.1924, D. H. Linder s/n, 1991, sobre corteza (GAM 5950, ISOTIPO de Hypoxylon aeruginosum).

Hypoxylon anthochroum Berk. et Broome, J. Linn. Soc. Bot. 14: 122. 1873.

Especímenes examinados: Chiapas, Tuxtla Gutiérrez, Zoológico Miguel Alvarez del Toro, 22.V.1988, San Martín 706, sobre madera en un bosque tropical alterado (ITCV; JDR). Quintana Roo, municipio de Othón P. Blanco, km 12 carretera Cafetal-Mahahual, 16.XI.1988, San Martín 1495 (cultivada), sobre madera en un bosque tropical bajo subcaducifolio con mangle (ITCV; JDR); San Felipe Bacalar, 10.XI.1988, San Martín 172 (cultivada), 1224A (cultivada) y 1224B, sobre madera en un acahual (ITCV; JDR). Nuevo León, municipio de Santiago, El Cercado, 10.XI.1986, Moreno 22, sobre madera en un matorral submontano con Quercus spp. (ITCV; JDR). Oaxaca, Temazcal, 7.X.1988, San Martín 1055, sobre madera en un bosque tropical mediano subcaducifolio (ITCV; JDR); 8.X.1988, San Martín 1113, sobre madera en un bosque tropical mediano subcaducifolio (ITCV; JDR).

Espécimen adicional examinado: Sri Lanka, XI.1867, G. H. K. Thwaite 160, sobre corteza (K, LECTOTIPO [seleccionado por Miller (1961)]; BPI; NY, ISOLECTOTIPOS de Hypoxylon anthochroum). 
Hypoxylon cinnabarinum (Henn.) Y.-M. Ju et J. D. Rogers, Mycol. Mem. 20. p. 99. 1996.

Espécimen examinado: Tabasco, municipio de Cárdenas, alrededores del antiguo Colegio Superior de Agricultura Tropical, 7.XII.1988, San Martín 1250 (cultivada), sobre madera en un acahual (ITCV).

Espécimen adicional examinado: Nummularia cinnabarina Henn., Brasil, Santa Catarina, prov. de Blumenau, A. Möller s/n, sobre corteza (S, LECTOTIPO).

Hypoxylon crocopeplum Berk. et M. A. Curtis apud Berk., Grevillea 4: 49. 1875.

Especímenes examinados: Quintana Roo, municipio de Othón P. Blanco, San Felipe Bacalar, 7.XII.1986, San Martín 80 (cultivada), sobre madera en un acahual (ITCV; JDR). Tamaulipas, municipio de Casas, km 66 carr. Soto La Marina-Cd. Victoria, 31.VIII.1988, San Martín 1087 (cultivada), sobre madera en matorral alto (ITCV; JDR); cabecera municipal de Gómez Farías, 2.IX.1988, San Martín 1054 (cultivada), sobre madera en un bosque tropical mediano subcaducifolio (ITCV; JDR).

Espécimen adicional examinado: Estados Unidos de América, Carolina del Sur, $H$. W. Ravenel s/n, Carolina Inferior, 1906, ¿sobre corteza de Quercus? (K, HOLOTIPO; BPI, ISOTIPO de $H$. crocopeplum).

Notas: Martin (1969) citó a H. crocopeplum de San Blas, Nayarit.

El espécimen que a continuación se menciona, no obstante presentar la superficie estromática de color blanco, tiene el resto de sus caracteres como los de $\mathrm{H}$. crocopeplum: Quintana Roo, municipio de Othón P. Blanco, Reserva de la Biosfera Sian Ka'an, 15.XI.1988, San Martín 1322A (cultivada), sobre madera en un bosque tropical mediano subcaducifolio (ITCV; JDR). La recolecta San Martín 1366 [Quintana Roo, municipio de Othón P. Blanco, Reserva de la Biosfera Sian Ka'an, 15.XI.1988, (cultivada), sobre madera en un bosque tropical mediano subcaducifolio (ITCV)] tiene la fase teleomórfica típica de $H$. crocopeplum, pero su anamorfo es del tipo Nodulisporium Preuss y quizás represente una nueva especie.

Hypoxylon dieckmannii Theiss., Ann. Mycol. 6: 346. 1908.

Especímenes examinados: Oaxaca, Temazcal, 7.X.1988, San Martín 1057 (cultivada), sobre madera en un bosque tropical mediano subcaducifolio (ITCV; JDR). Quintana Roo, municipio de Othón P. Blanco, ejido La Unión, 8.XII.1986, San Martín 103 y 61, sobre madera en un bosque tropical mediano subcaducifolio (ITCV; JDR). Tamaulipas, cabecera municipal de Gómez Farías, IX.1987, San Martín 75, sobre madera en un bosque tropical mediano subcaducifolio (ITCV; JDR).

Espécimen adicional examinado: Brasil, San Leopoldo, VIII.1907, F. Theissen s/n, sobre corteza (BPI 11493 ex J. Rick; GAM 2340; S, SINTIPOS de Hypoxylon dieckmannii).

Hypoxylon duranii J. D. Rogers, Mycotaxon 23: 429. 1985.

Espécimen examinado: México, Yucatán, Ruinas de Chichén Itzá, XI.1984, R. Durán $s / n$, sobre corteza de ¿Acacia? (WSP 67597, HOLOTIPO de H. duranii). Quintana Roo, municipio de Othón P. Blanco, San Felipe Bacalar, 31.VIII.1987, San Martín 559, sobre madera de Lysiloma latisiliqua (L.) Benth. en un acahual (ITCV; JDR).

Nota: Al parecer esta especie produce su estado teleomórfico en madera de leguminosas. 
Hypoxylon erythrostroma J. H. Miller, Mycologia 25: 323. 1933.

Especímenes examinados: Chiapas, municipio de Palenque, ruinas de Palenque, 2.VI.1988, San Martín 670, sobre madera en un bosque tropical alto perennifolio (ITCV; JDR). Quintana Roo, municipio de Othón P. Blanco, ejido La Unión, 31.VIII.1987, San Martín 57, sobre madera de Dendropanax arboreus (L.) Planch. et Decne. en un bosque tropical mediano subcaducifolio (ITCV; JDR); San Felipe Bacalar, 7.XII.1986, San Martín 80B, sobre madera en un acahual (ITCV; JDR). Tamaulipas, municipio de Gómez Farías, Reserva de la Biosfera EI Cielo, alt. 1100 m, 12.VIII.1988, Chacón Jiménez 433 (cultivada), sobre madera en un bosque mesófilo de montaña (ITCV; JDR). Veracruz, municipio de San Andrés Tuxtla, Catemaco, Estación Biológica Los Tuxtlas de la Universidad Nacional Autónoma de México, 4.XI.1988, San Martín 1378, sobre madera en un bosque tropical alto perennifolio (ITCV; JDR).

Espécimen adicional examinado: Estados Unidos de América, Florida, Daytona, I.1898, R. Thaxter $s / n$, Hypoxylon no. 2, ¿sobre madera descortezada y ennegrecida de Ulmus? (GAM 2374, ISOTIPO de Hypoxylon erythrostroma).

Hypoxylon fendleri Berk. ex Cooke, Grevillea 11: 132. 1883.

Especímenes examinados: Campeche, municipio de Escárcega, Estación Experimental Forestal Ing. Eduardo Sangri Serrano, 9.XI.88, San Martín 1484, sobre madera en un acahual (ITCV; JDR). Oaxaca, Temazcal, 8.X.88, San Martín 1119, sobre madera en un bosque tropical mediano subcaducifolio (ITCV; JDR). Quintana Roo, municipio de Othón P. Blanco, ejido La Unión, 8.XII.86, San Martín 42 y 43, sobre madera en un bosque tropical mediano subcaducifolio (ITCV; JDR); ibid., 12.XI.88, San Martín 1274, sobre madera en un bosque tropical mediano subcaducifolio (ITCV; JDR).Tamaulipas, cabecera municipal de Gómez Farías, 14.X.86, San Martín 30; 21.II.88, Chacón Jiménez 241, sobre madera en un bosque tropical mediano subcaducifolio (ITCV; JDR).

Espécimen adicional examinado: Venezuela, sin fecha, colector no identificado, sobre corteza (K \#261, HOLOTIPO de Hypoxylon fendleri).

Hypoxylon sp. aff. ferrugineum Otth., Mitth. Naturf. Ges. Bern 1868: 41. 1868.

Estromas pulvinados, con protrusiones periteciales inconspicuas, de 1-4 $\mathrm{mm}$ de largo x 1-2 mm de ancho x 0.6-0.8 mm de grueso; superficie de color sepia (60); con gránulos de color anaranjado pálido a anaranjado pálido café inmediatamente abajo de la superficie y entre los peritecios, con pigmento extraíble con $\mathrm{KOH}$ de color anaranjado (7); tejido bajo la capa peritecial inconspicuo. Peritecios esféricos, de 0.3-0.4 mm de diámetro. Ostiolos umbilicados. Ascos cilíndricos, octosporados, de 110-135 $\mu \mathrm{m}$ de largo total x 8-11 $\mu \mathrm{m}$ de ancho, la parte esporígena de 80-105 $\mu \mathrm{m}$ de largo, con anillo apical ausente o reducido, inamiloide. Ascosporas de color café a café obscuro, elipsoides inequilaterales, con extremos estrechamente redondeados, de 15-18 x 6.5-7.5 $\mu \mathrm{m}$, con línea germinal algo sigmoide a todo lo largo del propágulo en el lado convexo; perisporio dehiscente en $\mathrm{KOH}$ a $10 \%$, con ornamentación helicoidal inconspicua; episporio liso.

Espécimen examinado: Chiapas, municipio de La Trinitaria, Lagunas de Montebello, 24.V.88, San Martín 798, sobre madera en un bosque de pino-encino (ITCV; JDR).

Espécimen adicional examinado: Suiza, Berna, sin datos de colector y fecha, 21, sobre corteza de Tilia (G, LECTOTIPO de Hypoxylon ferrugineum). 
Notas: Este hongo se aproxima a $H$. ferrugineum en la morfología general de su estroma y en el tamaño de sus ascosporas, pero difiere en que al aparecer carece de anillo apical en el asco, y de presentarlo, éste no reacciona al reactivo de Melzer y sus ascosporas son poco variables. Asimismo, $H$. ferrugineum crece exclusivamente sobre madera de Tilia spp. (Miller, 1961).

Por lo anterior, los autores consideran a la recolecta mexicana como afín a $H$. ferrugineum, hasta tener datos sobre su(s) hospedante(s) y conexión anamórfica.

Hypoxylon haematostroma Mont., R. De La Sagra, FI. Cuba. 344. 1842.

Especímenes examinados: Campeche, municipio de Escárcega, Estación Experimental Forestal Ing. Eduardo Sangri Serrano, 9.XI.88, San Martín 1185, sobre madera en un bosque tropical mediano subcaducifolio (ITCV; JDR). Chiapas, municipio de Palenque, ruinas de Palenque, 8.XI.88, San Martín 1172, sobre madera en un bosque tropical alto perennifolio (ITCV; JDR). Oaxaca, Temazcal, 8.X.88, San Martín 1130, sobre madera en un bosque tropical mediano subcaducifolio (ITCV; JDR). Quintana Roo, municipio de Felipe Carrillo Puerto, sin fecha, San Martín 74, sobre madera en un bosque tropical mediano subcaducifolio (ITCV); municipio de Othón P. Blanco, San Felipe Bacalar, sin fecha, San Martín 73, sobre madera en un acahual (ITCV); ejido La Unión, 8.XII.86, San Martín 41; ibid., 12.XI.88, San Martín 1282, sobre madera en un bosque tropical mediano subcaducifolio (ITCV; JDR); ibid., 31.VIII.87, San Martín 315, sobre madera de Thrinax radiata Lodd. ex. J.A. \& J.H. Schult. (guano chit) en un bosque tropical mediano subcaducifolio (ITCV; JDR); Reserva de la Biosfera Sian Ka'an, 15.XI.88, San Martín 1363, sobre madera en un bosque tropical mediano subcaducifolio (ITCV; JDR). Tamaulipas, cabecera municipal de Gómez Farías, sin fecha, San Martín 20, sobre madera en un bosque tropical mediano subcaducifolio (ITCV); ibid., 2.IX.88, San Martín 1100, sobre madera en un bosque tropical mediano subcaducifolio (ITCV; JDR).

Espécimen adicional examinado: Cuba: Ramón de la Sagra $s / n$, sobre madera (BPI 55132; K, TIPO de Hypoxylon haematostroma).

Notas: Hypoxylon haematostroma fue citada primero del estado de Veracruz (como H. veracrucis) por Cooke (1883), posteriormente Martin (1969) la registró de San Blas, Nayarit.

Hypoxylon howeianum Peck, Annual Rep. New York State Mus. 24: 98. 1871.

Especímenes examinados: Coahuila, municipio de Arteaga, La Siberia, alt. $2600 \mathrm{~m}$, sin fecha, San Martín 6, sobre madera en un bosque de pino-encino (ITCV; JDR). Nuevo León, municipio de Santiago, ejido Laguna de Sánchez, La Camotera, alt. 1600 m, 19.Il.84, Tinoco Alfaro 4, sobre madera en un bosque de pino-encino (UNL).

Espécimen adicional examinado: Estados Unidos de América, Nueva York, C. $H$. Peck $s / n$, sobre madera de Pyrus malus (NYS, HOLOTIPO; BPI-CLS, ISOTIPO de Hypoxylon howeianum).

Nota: Al parecer, esta especie se distribuye en el territorio mexicano en bosques norteños de pino-encino.

Hypoxylon hypomiltum Mont., Ann. Sci. Nat. Bot. sér. II. 13: 356.1840.

Espécimen examinado: Tabasco, La Venta, 6.XI.88, San Martín 1279 (cultivado), sobre madera en un acahual (ITCV; JDR). 
Espécimen adicional examinado: Guyana Francesa, 1879, Leprieur 371 (K, LECTOTIPO de Hypoxylon hypomiltum).

Hypoxylon investiens (Schwein.) M. A. Curtis, Geol. Nat. Hist. Surv. North Carolina, pt. III, p. 140. 1867.

Especímenes examinados: Tabasco, municipio de Cárdenas, Colegio Superior de Agricultura Tropical, 7.XI.88, San Martín 1360 (cultivada), sobre madera en un acahual (ITCV; JDR). Tamaulipas, cabecera municipal de Gómez Farías, IX.87, San Martín 629; ibid., VII.1988, San Martín 1007; ibid., 21.II.88, Chacón 235, sobre madera en un bosque tropical mediano subcaducifolio (ITCV; JDR); municipio de Ocampo, 2.VIII.1987, San Martín 524, sobre madera en un bosque mediano subcaducifolio (ITCV; JDR). Veracruz, municipio de San Andrés Tuxtla, cascadas de Eyipantla, 5.XI.88, San Martín 1401, sobre madera de Ceiba pentandra (L.) Gaertn. en un bosque tropical mediano subcaducifolio (ITCV; JDR).

Espécimen adicional examinado: Estados Unidos de América, Carolina del Norte, Salem y Pennsylvania, Bethlehem, sin datos de colector y número, sobre madera descortezada (PH 1210, ISOTIPO de Sphaeria investiens).

Hypoxylon jecorinum Berk. et Ravenel apud Berk., Grevillea 4: 50. 1875.

Especímenes examinados: Nuevo León, municipio de Santiago, El Cercado, 26.VIII.84, Jesús García 4581, sobre madera en un matorral submontano con Quercus spp. (ITCV; JDR); ibid., IX.87, San Martín 392 (cultivada), sobre madera de Diospyros texana Scheele en un matorral submontano con Quercus spp. (ITCV; JDR). Tamaulipas, Ciudad Victoria, Los Troncones, sin fecha, Lucrecia García 2, sobre madera en un matorral submontano con elementos de vegetación riparia (ITCV).

Espécimen adicional examinado: Estados Unidos de América, Carolina del Sur, $H$. W. Ravenel 1560, sobre troncos de Acer rubrum L., (K, LECTOTIPO; BPI, ISOLECTOTIPO de Hypoxylon jecorinum).

Nota: Medel et al. (1989) describieron e ilustraron una recolecta de H. jecorinum del estado de Hidalgo.

Hypoxylon lenormandii Berk. et M. A. Curtis apud Berk., J. Linn. Soc. Bot. 10: 385. 1869. (como "lenormandi").

Especímenes examinados: Campeche, municipio de Escárcega, Estación Experimental Forestal Ing. Eduardo Sangri Serrano, 9.XI.88, San Martín 1211, sobre madera en una plantación experimental de árboles tropicales (ITCV; JDR); ibid., 9.XI.88, San Martín 1458, sobre madera en un acahual (ITCV; JDR). Chiapas, municipio de Ocosingo, Reserva de la Biosfera Montes Azules, 27.V.88, San Martín 817, sobre madera en un bosque tropical alto perennifolio (ITCV; JDR); municipio de Palenque, Ruinas de Palenque, 8.XI.88, San Martín 1428 (cultivada), sobre madera en un bosque tropical alto perennifolio (ITCV; JDR). Nuevo León, municipio de Santiago, El Cercado, IX.87, San Martín 396, sobre madera en un matorral submontano con Quercus spp. (ITCV; JDR). Quintana Roo, municipio de Othón P. Blanco, San Felipe Bacalar, 10.XI.88, San Martín 1207, sobre madera en un acahual (ITCV; JDR). Tamaulipas, municipio de Aldama, ejido La Cruz, Barra del Tordo, 10.IX.88, San Martín 1099, sobre madera en un acahual (ITCV; JDR); municipio de Gómez Farías, IX.86, San Martín 16, sobre madera en un bosque tropical mediano subcaducifolio (ITCV; 
JDR); ibid., 1987, San Martín 470, sobre madera en un bosque tropical mediano subcaducifolio (ITCV; JDR); ibid., VII.87, San Martín 937, sobre madera en un bosque tropical mediano subcaducifolio (ITCV; JDR); ibid., 2.IX.88, San Martín 1045, sobre madera en un bosque tropical mediano subcaducifolio (ITCV; JDR); municipio de Ocampo, X.87, Chacón 203, sobre madera en un bosque tropical mediano subcaducifolio (ITCV; JDR); ibid., cerro El Tigre, 11.VIII.88, Chacón Jiménez 490, sobre madera en un bosque tropical bajo subcaducifolio (ITCV; JDR).

Espécimen adicional examinado: Cuba: $C$. Wright 486, sobre madera descortezada (K, HOLOTIPO de Hypoxylon lenormandii).

NOTA: Martin (1969) citó a $H$. lenormandii (como $H$. oodes) de Mazatlán y San Blas en los estados de Sinaloa y Nayarit, respectivamente.

Hypoxylon lividipigmentum San Martín, Y.-M. Ju et J. D. Rogers, Mycol. Mem. 20. p. 145. 1996.

Especímenes examinados: Oaxaca, Temazcal, 8.X.88, San Martín 1139 (cultivada), sobre madera en un bosque tropical mediano subcaducifolio (ITCV; JDR). Quintana Roo, municipio de Othón P. Blanco, ejido La Unión, 8.XII.86, San Martín 96, sobre madera en un bosque tropical mediano subcaducifolio (ITCV, HOLOTIPO; JDR, ISOTIPO de $H$. lividipigmentum).

Hypoxylon cf. macrocarpum Pouzar, Ceská Mykol. 32: 19. 1978.

Especímenes examinados: Campeche, municipio de Escárcega, Estación Experimental Forestal Ing. Eduardo Sangri Serrano, 9.XI.88, San Martín 1239, sobre madera de Nectandra sp. (laurelillo) en un bosque tropical mediano subcaducifolio (ITCV; JDR); ibid., San Martín 1479, sobre madera en un acahual (ITCV; JDR). Quintana Roo, municipio de Othón P. Blanco, ejido La Unión, 8.XII.86, km 12 carr. Cafetal-Mahahual, 16.XI.88, San Martín 1330, sobre madera en un bosque tropical bajo subcaducifolio con mangle (ITCV; JDR). Tamaulipas, cabecera municipal de Gómez Farías, 2.IX.88, San Martín 1015, sobre madera en un bosque tropical mediano subcaducifolio (ITCV; JDR).

Espécimen adicional examinado: Checoslovaquia, Eslovaquia, 25.X.1972, Z. Pouzar, sobre madera descortezada de Fraxinus angustifolia subsp. danubialis (PR 807840, HOLOTIPO de Hypoxylon macrocarpum).

Notas: El teleomorfo de las recolectas de México es como el del tipo de $H$. macrocarpum, pero el anamorfo, aunque es del tipo Virgariella Hughes, no presenta las regiones conidiógenas infladas después de la conidiogénesis.

Hypoxylon monticulosum Mont., Syll. Gen. Sp. Crypt. p. 214. 1856.

Especímenes examinados: Chiapas, municipio de Ocosingo, ejido Pico de Oro, 31.V.88, San Martín 878 y 882 , sobre madera en un bosque tropical mediano subcaducifolio (ITCV; JDR); municipio de Tuxtla Gutiérrez, Cañón de El Sumidero, 22.V.88, San Martín 716, sobre madera en un bosque tropical bajo caducifolio alterado (ITCV; JDR); Tuxtla Gutiérrez, Zoológico Miguel Alvarez del Toro, 22.V.88, San Martín 706, sobre madera en un bosque tropical alterado (ITCV; JDR). Michoacán, municipio de Aquila, Colola, 8.VIII.88, San Martín 987, sobre madera en un bosque tropical mediano subcaducifolio (ITCV; JDR). Nuevo León, municipio de Santiago, El Cercado, 23.IX.88, San Martín 1158, sobre madera 
en un matorral submontano con Quercus spp. (ITCV; JDR). Oaxaca, Temazcal, 8.X.88, San Martín 1111, 1114 y 1137, sobre madera en un bosque tropical mediano subcaducifolio (ITCV; JDR). Quintana Roo, municipio de Othón P. Blanco, San Felipe Bacalar, 8.XII.86, San Martín 78, sobre madera en un acahual (ITCV; JDR); ibid., 10.XI.88, San Martín 1228, sobre madera en un acahual (ITCV; JDR). Tabasco, La Venta, 6.XI.88, San Martín 1272, sobre madera en un acahual (ITCV; JDR). Tamaulipas, municipio de Aldama, ejido La Cruz, Barra del Tordo, 1.IX.88, San Martín 1074, sobre madera en un acahual (ITCV; JDR); municipio de Gómez Farías, ejido Alta Cima, 1.XI.87, Chacón-Jiménez 56, sobre madera en un bosque mesófilo de montaña (ITCV; JDR); cabecera municipal de Gómez Farías, 14.IX.88, San Martín 1119, sobre madera en un bosque tropical mediano subcaducifolio (ITCV; JDR); municipio de Ocampo, Colonia Santa María Guadalupe, 28.III.88, Baldazo 205, sobre madera en un bosque tropical mediano subcaducifolio (ITCV; JDR); ibid., 16.V.88, San Martín 669 y 674, sobre madera en un bosque tropical mediano subcaducifolio (ITCV; JDR).

Espécimen adicional examinado: Guyana Francesa, Cayena, C. Leprieur 1176, sobre madera muerta (FH, ISOTIPO de Hypoxylon monticulosum).

Hypoxylon olivicolor San Martín, Y.-M. Ju et J. D. Rogers, Mycol. Mem. 20. p. 159. 1986. Espécimen examinado: Campeche, municipio de Escárcega, Estación Experimental Forestal Ing. Eduardo Sangri Serrano, 9.XI.88, San Martín 1439, sobre madera de Exostema mexicanum Gray en un bosque tropical mediano subcaducifolio (ITCV, HOLOTIPO; JDR, ISOTIPO de $H$. olivicolor).

Hypoxylon perforatum (Schwein.: Fr.) Fr., Summa Veg. Scand. II. p. 384. 1849.

Espécimen examinado: Nuevo León, municipio de Santiago, El Cercado, 16.IV.88, San Martín 428, sobre madera en un matorral submontano con Quercus spp. (ITCV; JDR).

Espécimen adicional examinado: Estados Unidos de América, Carolina del Norte, Salem y Pennsylvania, Bethlehem, sin datos de colector y número, sobre corteza (PH 1194, LECTOTIPO de Sphaeria perforata Schwein.: Fr.).

Hypoxylon placentiforme Berk. et M. A. Curtis, J. Linn. Soc., Bot. 10: 383. 1869.

Especímenes examinados: Campeche, municipio de Escárcega, Estación Experimental Forestal Ing. Eduardo Sangri Serrano, 9.XI.88, San Martín 1192B, sobre madera en un bosque tropical mediano subcaducifolio (ITCV; JDR). Jalisco, municipio de Cuautitlán, Sierra de Manantlán, El Rincón de Manantlán, camino de El Chonte, alt. 1450 m, 12.V.85, Guzmán-Dávalos 2782, sobre madera en un bosque de encino alterado (IBUG). Nuevo León, municipio de Santiago, El Cercado, 23.X.88, San Martín 1156, sobre madera en un matorral submontano con Quercus spp. (ITCV). Tamaulipas, cabecera municipal de Gómez Farías, 14.X.86, San Martín 28, sobre madera en un bosque tropical mediano subcaducifolio (ITCV; JDR); ibid., XI.87, Chacón 361 (cultivada), sobre madera en un bosque mixto de encinos con elementos tropicales (ITCV; JDR); ibid., 2.XI.88, San Martín 1073 (cultivada); ibid., 14.IX.88, San Martín 1131 (cultivada), sobre madera en un bosque tropical mediano subcaducifolio (ITCV: JDR).

Espécimen adicional examinado: Cuba: C. Wright 492, sobre madera (K, LECTOTIPO de Hypoxylon placentiforme). 
Hypoxylon polyporum (Starb.) Y.-M. Ju et J. D. Rogers, Mycol. Mem. 20. p. 171. 1996.

Especímenes examinados: Quintana Roo, municipio de José María Morelos, 12.I.86, Guevara 745 y Guevara s/n, sobre madera en un acahual (ITCV; JDR). Tamaulipas, municipio de Ocampo, 16.V.88, San Martín 631, sobre madera en un bosque tropical mediano subcaducifolio (ITCV; JDR).

Espécimen adicional examinado: Argentina, Jujuy, Quinta Privada Laguna de la Brea, 16.VI.1901, R. E. Fries 81, sobre madera (S, HOLOTIPO de Penzigia polyporus).

Hypoxylon rickii Y.-M. Ju et J. D. Rogers, Mycol. Mem. 20. p. 174. 1996.

Espécimen examinado: Oaxaca, Temazcal, 8.X.1988, San Martín 1126 (cultivada), sobre madera en un bosque tropical mediano subcaducifolio (ITCV).

Espécimen adicional examinado: Hypoxylon rubiginosum var. rickii Bres., Brasil, J. Rick 303, sobre madera descortezada, (NY, HOLOTIPO de Hypoxylon rickii).

Hypoxylon rubigineoareolatum Rehm apud Theiss., Ann. Mycol. 6: 345. 1908.

Espécimen examinado: Tamaulipas, brecha entre el ejido El Gavilán y el ejido San Miguel, municipio de San Carlos, alt. 705 m, 14.VIII.1998, San Martín 4004T, sobre madera en un matorral submontano (ITCV).

Espécimen adicional examinado: Brasil, San Leopoldo, F. Theissen, J. Rick AustroAmer. Exs. 306, sobre corteza (GAM 2930 y 12798, SINTIPOS de H. rubigineoareolatum).

Nota: Al igual que $H$. monticulosum Mont., el estroma joven de $H$. rubigineoareolatum presenta una superficie pruinosa de color rojo ladrillo a café, que al contacto con $\mathrm{KOH}$ a $10 \%$ libera un pigmento de color sepia; los estromas maduros de ambas especies son de color negruzco, sin superficie pruinosa y no liberan pigmentos al contacto con $\mathrm{KOH}$ a $10 \%$. de Brasil.

Al parecer, este es el primer registro de la presencia de $H$. rubigineoareolatum fuera

Hypoxylon cf. rubiginosum (Pers.: Fr.) Fr., Summa. Veg. Scand. II. p. 384. 1849.

Espécimen examinado: Nuevo León, municipio de Santiago, El Cercado, 23.X.88, San Martín 1151, sobre madera en un matorral submontano con Quercus spp. (ITCV; JDR).

Espécimen adicional examinado: Estados Unidos de América, localidad, colector y fecha desconocidos, sobre corteza (L 910, 263-1194, LECTOTIPO [seleccionado por Miller (1961)] de Sphaeria rubiginosa).

Nota: A diferencia de las recolectas de $H$. rubiginosum s. str. que producen in vitro estructuras conidiógenas del tipo Nodulisporium, la colección mexicana las genera del tipo Virgariella.

H. cf. samuelsii Y.-M. Ju et J. D. Rogers, Mycol. Mem. 20. p. 180. 1996.

Estromas efuso pulvinados, planos, con protrusiones periteciales discretas, de $1-3 \mathrm{~cm}$ de largo x 0.5-1 cm de ancho. Superficie estromática de color rojo ladrillo (39) o rojo ladrillo obscuro (60) a rojo vino (84); con gránulos de color anaranjado pálido a café amarillento bajo la superficie y entre los peritecios, con pigmentos extraíbles con $\mathrm{KOH}$ a $10 \%$ de color lúteo (12), anaranjado (7) o escarlata (5). Peritecios obovoides, de 0.2-0.3 mm de diámetro x 0.45-0.8 mm de alto. Ostiolos umbilicados. Ascos cilíndricos, octosporados, de 105-118.5 $\mu \mathrm{m}$ de largo total x 7.5-8 $\mu \mathrm{m}$ de ancho, la parte esporígena de 53-54.5 $\mu \mathrm{m}$ de largo, con anillo apical discoide, amiloide, de 2-2.5 $\mu \mathrm{m}$ de ancho x 0.8-1 $\mu \mathrm{m}$ de alto. Ascosporas de color 
café a café obscuro, unicelulares, elipsoidales, casi equilaterales, con extremos redondeados, infrecuentemente con un extremo constreñido, de (6.5-)7-9(-10.5) x 5-5.5(-6.5) $\mu \mathrm{m}$, con línea germinal recta, muy corta, en el lado convexo, con perisporio indehiscente en $\mathrm{KOH}$ a $10 \%$; episporio liso.

Espécimen examinado: Tamaulipas, municipio de Victoria, El Madroño, 12.X.1995, San Martín 5191T, sobre madera en un bosque de encino (ITCV).

Espécimen adicional examinado: Guyana Francesa: Mauroini, R. Superior, vic. Monpé Soula, 28.VIII.1987, G. J. Samuels 6098, sobre madera (NY, HOLOTIPO; WSP, ISOTIPO de Hypoxylon samuelsii).

Nota: El hongo arriba descrito tiene los colores del estroma, los pigmentos y los caracteres de sus ascosporas como los de $H$. samuelsii, pero difiere en que sus ascosporas son más anchas i. e., 5-5.5(-6.5) $\mu \mathrm{m}$ vs (3-)3.5-5 $\mu \mathrm{m}$ y en que al parecer $H$. samuelsii se distribuye exclusivamente en Australia e Indonesia. Asimismo, la recolecta de México se aproxima a $\mathrm{H}$. hypomiltum, pero esta especie tiene ascosporas con extremos casi agudos con línea germinal muy corta, sigmoide y el perisporio es dehiscente en $\mathrm{KOH}$ a $10 \%$.

Hypoxylon shearii Y.-M. Ju et J. D. Rogers var. shearii, Mycol. Mem. 20. p.182. 1996.

Estromas glomerulados conteniendo pocos peritecios, con protrusiones periteciales conspicuas, de 1.5-3 mm de ancho x 0.8-1 mm de alto. Superficie estromática cuando joven de color café claro (45), café (87) o rojo vino pálido (86), cuando madura con gránulos de color amarillo a anaranjado amarillento inmediatamente bajo la superficie y entre los peritecios, con pigmentos extraíbles con $\mathrm{KOH}$ de color lúteo (12); con escaso endostroma. Peritecios globosos, de $0.5-0.7 \mathrm{~mm}$ de diámetro. Ostiolos umbilicados, usualmente rodeados por un área pálida de 0.2-0.35 mm de diámetro. Ascos cilíndricos, octosporados, con estípite largo, de 126-151 $\mu \mathrm{m}$ de longitud total x 7-8(-10) $\mu \mathrm{m}$ de ancho, la parte esporígena de 66$76 \mu \mathrm{m}$ de largo, con anillo apical ausente o muy reducido, inamiloide. Ascosporas de color café a café obscuro, elipsoides inequilaterales, naviculares o crescénticas, con extremos estrechos a estrechamente redondeados, de 10.5-15 x 5.5-7 $\mu \mathrm{m}$, con línea germinal recta a todo lo largo del propágulo por el lado convexo; perisporio dehiscente en $\mathrm{KOH}$ a $10 \%$ con ornamentación helicoidal muy conspicua; episporio liso.

Especímenes examinados: Tamaulipas, municipio de Gómez Farías, ejido San José, 4.X.1992, San Martín 1443D y 1541T, sobre madera de Quercus sp. en un bosque mesófilo de montaña.

Espécimen adicional examinado: Estados Unidos de América, Louisiana, East Baton Rouge Parish, IV.1980, J. D. Rogers y J. P. Jones, sobre corteza de Quercus sp. (WSP 69637, HOLOTIPO de H. shearii var. shearii).

Nota: La variedad típica de Hypoxylon shearii es un nuevo registro para México. Al parecer el hongo fructifica exclusivamente en madera de Quercus spp. en bosques mesófilos de montaña.

Hypoxylon shearii var. minor San Martín, Y.-M. Ju et J. D. Rogers var. nov.

A varietate typica speciei differt ascis minoribus 108-114 $\mu \mathrm{m}$ longis et ascosporis (6.5-)7-8 x (3-)3.5-4 $\mu \mathrm{m}$.

Los caracteres teleomórficos de la variedad propuesta son como los de la variedad típica, con excepción del largo de ascos y ascosporas, que es de 108-114 $\mu \mathrm{m}$ y (6.5-)7-8 x (3-)3.5-4 $\mu \mathrm{m}$, respectivamente. 
Especímenes examinados: Tamaulipas, municipio de Victoria, El Madroño, 1986, San Martín 614, sobre madera de Quercus sp. en un bosque de encino (ITCV; JDR); ibid., alt. 1485 m, 5.IX.1995, San Martín 5079T, sobre madera de Quercus sp. en un bosque de encino (ITCV, HOLOTIPO de Hypoxylon shearii var. minor); ibid., alt. 1410 m, 17.XI.1996, sin datos del colector, sobre madera de Quercus aff. canbyi Trel. (ITCV).

Nota: Al igual que la variedad típica, Hypoxylon shearii var. minor fructifica en madera de Quercus. Al parecer, $H$. shearii var. shearii prospera en madera de encino presente en lugares con cantidades de precipitación mayores que aquellos donde comúnmente se encuentra $H$. shearii var. minor.

Hypoxylon sp. San Martín 23.

Estromas pulvinados a hemisféricos, arrugados cuando secos, de 3-8 $\mathrm{mm}$ de ancho x 1-3.5 mm de alto; superficie de color ámbar (9); con gránulos de color rojo ladrillo (39) a café anaranjado pálido inmediatamente abajo de la superficie y entre los peritecios, con pigmentos extraíbles con $\mathrm{KOH}$ de color lúteo (12); el tejido bajo la capa de peritecios de más de $3 \mathrm{~mm}$ de grueso, de color negro. Peritecios obovados, de 0.1-0.2 mm de diámetro x 0.2-0.3 mm de alto. Ostiolos umbilicados. Ascos cilíndricos, octosporados, de 100-130 $\mu \mathrm{m}$ de largo total x 7-9 $\mu \mathrm{m}$ de ancho, la parte esporígena de $65-75 \mu \mathrm{m}$, con anillo apical discoide, amiloide, de $1 \mu \mathrm{m}$ de alto $\times 2 \mu \mathrm{m}$ de ancho. Ascosporas de color café obscuro, unicelulares, elipsoides, casi equilaterales, con extremos ampliamente redondeados, de 7.5-10 x 4.5-6 $\mu \mathrm{m}$, con línea germinal recta a todo lo largo del propágulo por el lado convexo; perisporio indehiscente en $\mathrm{KOH}$ a $10 \%$; episporio liso.

Espécimen examinado: Nuevo León, municipio de Santiago, El Cercado, 10.XI.1986, San Martín 23, sobre madera en un matorral submontano con Quercus spp. (ITCV; JDR).

Nota: Este hongo se caracteriza por sus ascosporas casi equilaterales con extremos redondeados. El ejemplar seguramente representa una especie nueva, pero la colección consiste solamente de dos estromas, material muy escaso para designarlo como tipo.

Por otra parte, el taxon mexicano bien puede ser una especie de Sarcoxylon, pero sin datos de su anamorfo es preferible considerarlo tentativamente como Hypoxylon.

Hypoxylon sp. San Martín 227.

Estromas efuso-pulvinados con protrusiones periteciales inconspicuas, de $0.45-2 \mathrm{~cm}$ de largo x 0.3-2 cm de ancho; superficie cuando joven de color rojo ladrillo (39), negro brillante en la madurez; con tejido negruzco de consistencia carbonosa inmediatamente abajo y entre la capa peritecial, sin pigmentos extraíbles en $\mathrm{KOH}$ a $10 \%$; tejido inconspicuo bajo la capa peritecial. Peritecios esféricos, de 0.2-0.3 mm de diámetro. Ostiolos cónicopapilados. Ascos cilíndricos, octosporados, de 145-170 $\mu \mathrm{m}$ de largo total x 7-9.5 $\mu \mathrm{m}$ de ancho, la parte esporígena de 85-120 $\mu \mathrm{m}$, con anillo apical discoide, amiloide, de 1.5-2.5 $\mu \mathrm{m}$ de alto x 3-3.5 $\mu \mathrm{m}$ de ancho. Ascosporas de color café claro a café, elipsoides, casi equilaterales, con extremos redondeados a estrechamente redondeados, de 12.5-14.5 x 6.5$7.5 \mu \mathrm{m}$, con línea germinal recta a algo sigmoide, extendida a todo lo largo del propágulo; perisporio no dehiscente en $\mathrm{KOH}$ a $10 \%$; episporio liso.

Espécimen examinado: Tamaulipas, cabecera municipal de Gómez Farías, 17.VII.1987, San Martín 22, sobre madera en un bosque tropical mediano subcaducifolio (ITCV; JDR). 
Espécimen adicional examinado: Estados Unidos de América, Missouri, Parque Wakonda, 10.III.1983, J. D. Rogers, sobre madera descortezada (WSP 69640, HOLOTIPO; JDR, ISOTIPO de Hypoxylon submonticulosum).

Notas: La morfología teleomórfica de esta especie es como la de $H$. submonticulosum Y.-M. Ju y J. D. Rogers, excepto por sus ascosporas que son más equilaterales y grandes, a saber: $12.5-14.5 \times 6.5-7.5 \mu \mathrm{m}$ vs 9-12(-13.5) x 4-5 $\mu \mathrm{m}$, así como por la línea germinal extendida a todo lo largo del propágulo y el perisporio indehiscente en $\mathrm{KOH}$ a $10 \%$ (para descripción de H. submonticulosum ver Ju y Rogers, 1996).

Este material probablemente representa una nueva especie, pero dado que sus estromas son algo inmaduros y no contamos con datos de cultivos y anamorfos, resulta inapropiado designarlo como material tipo. El hongo parece estar muy relacionado con el complejo de $H$. monticulosum.

Hypoxylon subgilvum Berk. et Broome, J. Linn. Soc. Bot. 14: 120. 1873.

Especímenes examinados: Tamaulipas, cabecera municipal de Gómez Farías, 16.VII.1987, San Martín 226; ibid., 2.IX.1988, San Martín 1030 (cultivada), sobre madera en un bosque tropical mediano subcaducifolio (ITCV; JDR).

Nota: Las siguientes recolectas, no obstante presentar la superficie estromática de color rosado (61) a café rojo vino (86) y producir en cultivo áreas de esporulación de color rosa, se asignan a $H$. subgilvum: Campeche, municipio de Escárcega, Estación Experimental Forestal Ing. Eduardo Sangri Serrano, 9.XI.88, San Martín 1204, sobre madera de Nectandra sp. (laurelillo), en un bosque tropical mediano subcaducifolio (ITCV; JDR); ibid., San Martín 1237, sobre madera en un bosque tropical mediano subcaducifolio (ITCV; JDR); ibid., San Martín 1499, sobre madera en un acahual (ITCV; JDR).

Espécimen adicional examinado: Sri Lanka: XII.1868, G. H. K. Thwaite 1087, sobre corteza (K, HOLOTIPO de Hypoxylon subgilvum).

Hypoxylon subrutilum Starb., Bih. Kongl. Svenska Vetensk.-Akad. Handl. 27, 3: 10. 1901.

Especímenes examinados: Quintana Roo, municipio de Othón P. Blanco, ejido La Unión, XII.1986, San Martín 938, sobre madera en un bosque tropical mediano subcaducifolio (ITCV; JDR); San Felipe Bacalar, 7.XII.1986, San Martín 105, sobre madera en un acahual (ITCV; JDR). Tamaulipas, Ciudad Victoria, 16.IX.88, San Martín 1018B, sobre madera en matorral alto (ITCV; JDR).

Espécimen adicional examinado: Brasil, Rio Grande do Sul, Porto Alegre, 29.IX.1892, Malme $s / n$, sobre ramillas (S, HOLOTIPO de Hypoxylon subrutilum).

Hypoxylon symphyon A. Möller, Phycomyc. et Ascomyc. p. 308. 1901.

Espécimen examinado: Oaxaca, Temazcal, 8.X.1988, San Martín 1124, sobre madera en un bosque tropical mediano subcaducifolio (ITCV; JDR).

Espécimen adicional examinado: Brasil, Santa Catarina, Blumenau, VI.1892, A. Möller, sobre madera (S, TIPO de Hypoxylon symphyon).

Hypoxylon sp. aff. ticinense L. E. Petrini apud L. E. Petrini et Müller, Mycol. Helv. 1: 534. 1986.

Estromas repando-pulvinados, de $8-14 \mathrm{~mm}$ de ancho x 6-10 $\mathrm{mm}$ de alto; superficie de color rojo ladrillo (39), sepia (63), bayo (6) o rojo ladrillo obscuro (60); con gránulos de 
color rojo anaranjado bajo la superficie y entre los peritecios, con pigmentos extraíbles con $\mathrm{KOH}$ de color anaranjado (7); el tejido bajo la capa de peritecios de más de $0.9 \mathrm{~mm}$ de grueso, de color negro. Peritecios obovados a algo tubulares, de 0.1-0.2 mm de diámetro x 0.4-0.5 mm de alto. Ostiolos umbilicados. Ascos cilíndricos, octosporados, de 90-107 $\mu \mathrm{m}$ de largo total $\times 3$ 3-3.5 $\mu \mathrm{m}$ de ancho, la parte esporígena de 38-42 $\mu \mathrm{m}$, con anillo apical discoide, amiloide, de $0.8 \mu \mathrm{m}$ de alto $\times 1.5 \mu \mathrm{m}$ de ancho. Ascosporas de color café claro, unicelulares, elipsoides inequilaterales, con extremos estrechamente redondeados, de 5-5.5 x $2.5 \mu \mathrm{m}$, con línea germinal recta a algo sigmoide, extendida a todo lo largo del propágulo por el lado convexo; perisporio dehiscente en $\mathrm{KOH}$ a $10 \%$; episporio liso.

Especímenes examinados: Tamaulipas, municipio de Gómez Farías, ejido San José, 4.X.1992, San Martín 1505T y 1552T, sobre madera en un bosque mesófilo de montaña (ITCV).

Espécimen adicional examinado: Suiza, Bellinzona, Bosque de Moleno, XII.1983, E. Zenone $s / n$, sobre madera de Crataegus oxyacantha L. (JDR; WSP 67869, ISOSINTIPOS de Hypoxylon ticinense)..

Nota: Los caracteres teleomórficos de este hongo son muy similares a los de $H$. ticinense y $\mathrm{H}$. subgilvum Berk. et Broome var. microsporum (Abe) Y.-M. Ju et J. D. Rogers, taxa relativamente fáciles de separar con base en sus estados conidiales. En tanto no se tengan datos anamórficos de las recolectas mexicanas, los autores consideran a la especie como afín a $H$. ticinense.

\section{SECCION ANNULATA}

Hypoxylon annulatum (Schwein.: Fr.) Mont. apud C. Gay, FI. Chilena VII, p. 445. 1850.

Especímenes examinados: Chiapas, municipio de La Trinitaria, Lagunas de Montebello, 24.V.88, San Martín 806, sobre madera de Quercus sp. en un bosque de pinoencino (ITCV; JDR). Tamaulipas, municipio de Hidalgo, ejido Conrado Castillo, VII.87, San Martín 344, sobre madera de Quercus sp. en un bosque de pino-encino (ITCV; JDR).

Espécimen adicional examinado: Estados Unidos de América, Carolina del Norte, Salem y Pennsylvania, Bethlehem, sin datos de colector y número, sobre corteza (PH 1176, SINTIPO; BPI-CLS, ISOSINTIPO de Sphaeria annulata).

Hypoxylon cohaerens (Pers.: Fr.) Fr. var. microsporum J. D. Rogers et Cand., Mycologia 72: 826, 1980.

Espécimen examinado: Chiapas, municipio de San Cristóbal de las Casas, cerro El Huitepec, 4.VI.1988, San Martín 725B, sobre madera en bosque de pino-encino (ITCV; JDR). Tamaulipas, municipio de Gómez Farías, alrededores de La Gloria, 8.VII.1995, San Martín $1518 T$, sobre madera ¿de encino? en un bosque mesófilo de montaña (ITCV).

Espécimen adicional examinado: Francia, Los Pirineos (parte del Atlántico), bosque del hospital San Blas, 8.VII.1979, F. Condoussau 862, sobre madera de Quercus (WSP 63897, HOLOTIPO de Hypoxylon cohaerens var. microsporum).

Hypoxylon moriforme Henn., Bot. Jahrb. Syst. 23: 287. 1896.

Especímenes examinados: Chiapas, municipio de Ocosingo, Reserva de la Biosfera Montes Azules, 27.V.88, San Martín 807, sobre madera en un bosque tropical alto 
perennifolio (ITCV; JDR); municipio de Mapastepec, Cañada Honda, 10.VI.88, San Martín 890, sobre madera en un bosque tropical mediano subcaducifolio (ITCV; JDR); municipio de Jaltenango, vereda cerro El Triunfo-Palo Gordo, 11.VI.88, San Martín 915, sobre madera en un bosque mesófilo de montaña (ITCV; JDR). Quintana Roo, municipio de Othón P. Blanco, ejido La Unión, 8.XII.86, San Martín 33, sobre madera en un bosque tropical mediano subcaducifolio (ITCV; JDR); San Felipe Bacalar, 10.XI.88, San Martín 1303, sobre madera en un acahual (ITCV; JDR). Tamaulipas, municipio de Gómez Farías, ejido Conrado Castillo, 8.VIII.87, San Martín 201, sobre madera de Quercus sp. en un bosque de pinoencino (ITCV; JDR); Julilo, sin fecha, Chacón-Jiménez 53, sobre madera de Quercus sp. en un bosque de pino-encino (ITCV; JDR).

Espécimen adicional examinado: Samoa, Upolu, Reinecke $s / n$, sobre corteza (S, LECTOTIPO de Hypoxylon moriforme).

Hypoxylon multiforme (Fr.: Fr.) Fr., Summa Veg. Scand. II, p. 384. 1849.

Espécimen examinado: Tamaulipas, municipio de Gómez Farías, Rancho El Cielo, II.1995, San Martín 4092T, sobre madera en un bosque mesófilo de montaña (ITCV).

Espécimen adicional examinado: Nepal, Valle Yungma, alt. 11000 pies, J. D. Hooker $s / n$, sobre madera de Betula (ITCV).

Nota: La recolecta mexicana constituye el primer registro para el país. En China, Suecia y los Estados Unidos de América $H$. multiforme parece ser específico de Betula, género ausente en la Reserva de la Biosfera El Cielo; sin embargo, en la zona se encuentran otras Betulaceae como Ostrya, Carpinus y Alnus (Jesús García com. pers.).

Hypoxylon nitens (Ces.) Y.-M. Ju et J. D. Rogers, Mycol. Mem. 20. p. 220. 1996.

Espécimen examinado: Chiapas, municipio de Ocosingo, Reserva de la Biosfera Montes Azules, 28.V.1988, San Martín 792A (cultivada), sobre madera en un bosque tropical alto perennifolio (ITCV; JDR). Tamaulipas, municipio de Hidalgo, ejido Independencia, 27.IX.1997, San Martín 5888T, sobre madera en un matorral submontano (ITCV).

Espécimen adicional examinado: Malasia: Borneo, Sarawak, O. Beccari 10, sobre corteza (RO, HOLOTIPO de Rosellinia nitens).

Hypoxylon pseudostipitatum Y.-M. Ju et J. D. Rogers, Mycol. Mem. 20. p. 223. 1996. Espécimen examinado: Quintana Roo, municipio de Othón P. Blanco, ejido La Unión, 8.XII.1986, San Martín 401, sobre madera en un bosque tropical mediano subcaducifolio (ITCV; JDR). Localidad no especificada, C. L. Smith $s / n$, sobre madera, como $H$. pseudostipitatum Ellis et Macbr., ined. (BPI, HOLOTIPO de H. pseudostipitatum).

Hypoxylon purpureonitens Y.-M. Ju et J. D. Rogers, Mycol. Mem. 20. p. 224.

Espécimen examinado: Chiapas, municipio de Ocosingo, ejido Boca de Chajul, 25.V.1988, San Martín 862, sobre madera en un bosque tropical alto perennifolio (ITCV; JDR).

Espécimen adicional examinado: Brasil, Sierra Araca, 10.III.1984, G. J. Samuels 808, sobre corteza (NY, HOLOTIPO; WSP 69635, ISOTIPO de Hypoxylon purpureonitens). 
Hypoxylon stygium (Lév.) Sacc., Syll. Fung. I. p. 379. 1882.

Especímenes examinados: Chiapas, municipio de Ocosingo, ejido Pico de Oro, 3.VI.88, San Martín 879, sobre madera en un bosque tropical alto perennifolio (ITCV; JDR); municipio de Tuxtla Gutiérrez, Cañón de El Sumidero, 22.V.88, San Martín 715, sobre madera en un bosque tropical bajo caducifolio (ITCV; JDR). Nuevo León, municipio de Santiago, El Cercado, IX.87, San Martín 393, sobre madera en un matorral submontano con Quercus spp. (ITCV; JDR); ibid., sin fecha, Moreno 222; ibid., 23.X.88, San Martín 1162. Quintana Roo, municipio de Othón P. Blanco, San Felipe Bacalar, 16.XI.88, San Martín 1383, sobre madera en un acahual (ITCV; JDR); Reserva de la Biosfera Sian Ka'an, 15.XI.88, San Martín 1501, sobre madera en un bosque tropical mediano subcaducifolio (ITCV; JDR). Tamaulipas, cabecera municipal de Gómez Farías, 20.VII.88, San Martín 972, sobre madera en un bosque tropical mediano subcaducifolio (ITCV; JDR); El Nacimiento, 29.V.88, San Martín 623, sobre madera en un bosque tropical mediano subcaducifolio (ITCV; JDR). Veracruz, municipio de Catemaco, Estación Biológica Los Tuxtlas de la Universidad Nacional Autónoma de México, 4.XI.88, San Martín 1398, sobre madera en un bosque tropical alto perennifolio (ITCV; JDR).

Espécimen adicional examinado: República Dominicana, Santo Domingo, Poiteau $s / n$, sobre madera (PC, HOLOTIPO de Sphaeria stygia).

Hypoxylon thouarsianum (Lév.) C. G. Lloyd var. thouarsianum, Mycol. Writings 5: 26. 1919.

La descripción de esta especie se puede consultar en Miller (1961) y Ju y Rogers (1996).

Ascas cilíndricas, octosporadas en forma parcialmente biseriada, con pedicelos cortos, de 183-201 $\mu \mathrm{m}$ de largo total x 6.5-5 $\mu \mathrm{m}$ de ancho, la parte esporígena de 134$149 \mu \mathrm{m}$, con anillo apical ausente o muy reducido, inamiloide.

Especímenes examinados: Chiapas, municipio de La Trinitaria, Lagunas de Montebello, 24.V.88, San Martín 705, sobre madera en un bosque de pino-encino con Liquidambar sp. (ITCV; JDR). Coahuila, Agua Blanca, alt. 2450 m, 24.VI.84, M. González 60 , sobre madera en un bosque de pino-encino (ITCV; JDR). Jalisco, municipio de Autlán, Predio Las Joyas, El Laurelito, alt. 1900 m, 13.X.85, Guzmán-Dávalos 2833, sobre madera en un bosque mesófilo de montaña (IBUG); municipio de La Manzanilla de la Paz, km 3 carr. La Manzanilla-Valle Florido, alt. 1900 m, 23.VI.85, F. Trujillo 856, sobre madera en un bosque de encino (IBUG). Nuevo León, municipio de Santiago, cascadas Cola de Caballo, sin fecha, C. Reyna 25, sobre madera en un bosque de encino (ITCV; JDR). Tamaulipas, municipio de Gómez Farías, Reserva de la Biosfera El Cielo, sin fecha, J. García 5339, sobre madera en un bosque mesófilo de montaña (ITCV; JDR); Malacate, 31.III.88, Baldazo 206, sobre madera en un bosque mesófilo de montaña (ITCV; JDR); municipio de Hidalgo, ejido Conrado Castillo, 2.V.88, Lucrecia García 105 y 110, sobre madera de Quercus sp. en un bosque de encino (ITCV; JDR); ibid., VII.1988, Lucrecia García 121, sobre madera de Quercus sp. en un bosque mesófilo de montaña (ITCV; JDR); municipio de Victoria, El Madroño, 21.VI.88, Lucrecia García 203, sobre madera en un bosque de encino (ITCV; JDR).

Espécimen adicional examinado: Ecuador, Islas Galápagos, P. Thouars, (PC, HOLOTIPO de Sphaeria thouarsiana). 
Hypoxylon thouarsianum (Lév.) C. G. Lloyd var. macrosporum San Martín, Y.-M. Ju et J. D. Rogers, Mycol. Mem. 20. p. 228. 1996.

Especímenes examinados: Chiapas, municipio de La Trinitaria, Lagunas de Montebello, 25.V.88, San Martín 845, sobre madera en un bosque de encino-pino con Liquidambar sp. (ITCV, HOLOTIPO; JDR, ISOTIPO de H. thouarsianum var. macrosporum); ibid., 24.V.88, San Martín 800.

Nota: La diferencia más importante entre la variedad mexicana y la típica radica en que esta última presenta ascosporas más pequeñas i.e., 14-24 x 4-5.5 $\mu \mathrm{m}$ vs 24-27(-30) x 6-7 $\mu \mathrm{m}$.

Hypoxylon truncatum (Schwein.: Fr.) J. H. Miller, Trans. Brit. Mycol. Soc. 17: 130. 1932.

Especímenes examinados: Nuevo León, municipio de Santiago, El Cercado, 16.IV.88, San Martín 401, sobre madera en un matorral submontano con Quercus spp. y elementos riparios (ITCV; JDR). Quintana Roo, municipio de Othón P. Blanco, San Felipe Bacalar, 10.XI.88, San Martín 1356, sobre madera en un acahual (ITCV; JDR).

Espécimen adicional examinado: Estados Unidos de America, Carolina del Norte, Salem y Pennsylvania, Bethlehem, sin datos de colector y número, sobre corteza, material mezclado con Rosellinia corticium, (PH 1501, LECTOTIPO; BPI-CLS, ISOLECTOTIPO de Sphaeria truncata).

\section{AGRADECIMIENTOS}

Por su gentileza de facilitarnos la consulta de ejemplares tipo y otras de indudable valor para este estudio, los autores desean dejar constancia de su gratitud a los curadores de los siguientes herbarios: BPI-CLS, ENCB, FH, G, GAM, IBUG, K, L, LIN, NY, PC, PH, $\mathrm{RO}, \mathrm{S}$, UNL y XAL.

Por su ayuda en el trabajo de campo llevado a cabo en 12 estados del país, Felipe San Martín queda muy agradecido con las siguientes personas: Biól. José Guadalupe Avalos, Biól. Jorge Ayala Guajardo, Biól. Bertha Baldazo, Dr. Efrén Cázarez González, Biól. Santiago Chacón Jiménez, Biól. Javier Chavelas Pólito (quién también brindó facilidades para recolectar en el Campo Experimental del INIFAP en San Felipe Bacalar, Quintana Roo), Biól. Martha Lucrecia García y M. en C. María Concepción Herrera Monsiváis (quienes también auxiliaron a los autores en la identificación de plantas superiores), Biól. Jesús García, M. en C. Gonzalo Guevara, Biól. Francisco Quinto Adrián, M. en C. Arnulfo Moreno, y en especial con el Biól. José Castillo Tovar y Dr. Gastón Guzmán por su apoyo y guía.

\section{LITERATURA CITADA}

Cooke, M. C. 1883. Hypoxylon and its allies. Grevillea 11: 121-140.

Holmgren, P. K., N. H. Holmgren y L. C. Barnett. 1990. Index Herbariorum. I. The herbaria of the world. 8th Ed. New York Botanical Garden. Bronx. Nueva York. 693 pp.

Ju, Y.-M. y J. D. Rogers. 1996. A revision of the genus Hypoxylon. Mycol. Mem. 20. APS Press. St. Paul, Minnesota. 382 pp. 
Ju, Y.-M., J. D. Rogers y F. San Martín. 1997. A revision of the genus Daldinia. Mycotaxon 61: 243293.

Martin, P. 1969. Studies in the Xylariaceae: V. Euhypoxylon. J. S. African Bot. 35: 149-206.

Medel, R., S. Chacón y G. Guzmán. 1989. Especies conocidas y nuevos registros de Hypoxylon (Sphaeriales; Xylariaceae) en México. Rev. Mex. Mic. 5: 149-168.

Miller, J. H. 1961. A monograph of the world species of Hypoxylon. Univ. Georgia Press. Athens. 158 pp.

Petrini, L. E. y O. Petrini. 1985. Xylariaceous fungi as endophytes. Sydowia 38: 216-234.

Reyner, R. W. 1970. A mycological colour chart. Commonwealth Mycological Institute, Kew and British Mycological Society. 34 pp + Láminas I y II.

San Martín, F. 1992. A mycofloristic and cultural study of the Xylariaceae of Mexico. Ph. D. Thesis. Washington State University. Pullman, Washington. 560 pp.

San Martín, F. y P. Lavín. 1997. Datos sobre los géneros Entonaema y Ustulina (Pyrenomycetes, Xylariaceae). Acta Bot. Mex. 40: 25-35.

Van der Gucht, K., Y.-M, Ju y J. D. Rogers. 1997. New Hypoxylon species from Papua New Guinea and notes on some other taxa. Mycologia 89 (3): 503-511.

Aceptado para publicación en mayo de 1999. 